Check for updates

Cite this: RSC Adv., 2019, 9, 33814

\title{
Electrodeposited Pd/graphene/ZnO/nickel foam electrode for the hydrogen evolution reaction
}

\author{
Na Wang, $\uparrow^{\mathrm{a}}$ Bairui Tao, (D) $\uparrow^{\star a}$ Fengjuan Miao (D) *a and Yu Zang ${ }^{\mathrm{b}}$
}

Efficient electrocatalysts are crucial to water splitting for renewable energy generation. In this work, electrocatalytic hydrogen evolution from Pd nanoparticle-modified graphene nanosheets loaded on $\mathrm{ZnO}$ nanowires on nickel foam was studied in an alkaline electrolyte. The high electron mobility stems from the cylindrical $\mathrm{ZnO}$ nanowires and the rough surface on the graphene/ZnO nanowires increases the specific surface area and electrical conductivity. The catalytic activity arising from adsorption and desorption of intermediate hydrogen atoms by $\mathrm{Pd}$ nanoparticles improves the hydrogen evolution reaction efficiency. As a hydrogen evolution reaction (HER) catalyst, the $\mathrm{Pd} /$ graphene/ZnO/Ni foam $(\mathrm{Pd} /$ $\mathrm{G} / \mathrm{ZnO} / \mathrm{NF}$ ) nanocomposite exhibits good stability and superior electrocatalytic activity. Linear sweep voltammetry (LSV) revealed an overpotential of $-31 \mathrm{mV}$ and Tafel slope of $46.5 \mathrm{mV} \mathrm{dec}{ }^{-1}$ in $1 \mathrm{M} \mathrm{KOH}$. The economical, high-performance, and environmentally friendly materials have excellent prospects in hydrogen storage and hydrogen production.

Received 12th July 2019

Accepted 3rd October 2019

DOI: $10.1039 / c 9 r a 05335 b$

rsc.li/rsc-advances

$\mathrm{ZnO}$ is an n-type wide-bandgap semiconductor with high electron mobility as well as excellent optical, electronic and photocatalytic properties. ${ }^{14}$ Therefore, the graphene/ZnO hybrid may have large potential from the viewpoint of the hydrogen evolution reaction.

In this work, the Pd/graphene/ZnO/Ni foam (Pd/G/ZnO/NF) nanocomposite was fabricated by a hydrothermal method and electroplating and the HER activity was evaluated. The ZnO nanowires on the Ni foam provide high electron mobility to facilitate hydrogen evolution and graphene nanosheets improve the electrical conductivity and specific surface area.

\section{Experimental details}

\subsection{Materials and reagents}

hydrogen atoms on the electrode surface.

Among the non-metallic catalytic materials for the HER, carbon-based materials such as carbon black, carbon nanotubes, and graphene have aroused interest. ${ }^{8-10}$ Especially, graphene has good mechanical strength, large specific surface area, and high electrical and thermal conductivity ${ }^{11,12}$ and many strategies have been proposed to synthesize the proper nanoarchitectures to improve the catalytic efficiency. It has been shown that the electrocatalytic performance is affected by the specific surface area ${ }^{13}$ and metal catalysts fabricated on n-doped graphene have better durability and electrocatalytic activity.

${ }^{a}$ College of Communications and Electronics Engineering, Qiqihar University, Heilongjiang 161006, China.E-mail: tbr_sir@163.com; miaofengjuan@163.com; Fax: +86-452-2738748; Tel: +86-452-2742787

${ }^{b}$ College of Materials Science and Engineering, Qiqihar University, Wenhua Street 42, Qiqihar, China

$\dagger$ Na Wang and Bairui Tao are co-first authors.

The Ni foam (thickness of $0.5 \mathrm{~mm}$, pore density of $110 \mathrm{PPI}$, and areal density of $420 \mathrm{~g} \mathrm{~m}^{-2}$ ) was purchased from Suzhou Qiandingli Electronic Technology Co. Ltd. and graphene slurry (5 wt\%) was obtained from Suzhou Graphene Nanotechnology Co. Ltd. Palladium chloride $\left(\mathrm{PdCl}_{2}\right)$, ammonium chloride $\left(\mathrm{NH}_{4} \mathrm{Cl}\right)$, ammonia $\left(\mathrm{NH}_{3} \cdot \mathrm{H}_{2} \mathrm{O}\right)$, zinc acetate $\left(\mathrm{Zn}\left(\mathrm{CH}_{3} \mathrm{COO}\right)_{2}\right)$, zinc nitrate hexahydrate $\left(\mathrm{Zn}\left(\mathrm{NO}_{3}\right)_{2} \cdot 6 \mathrm{H}_{2} \mathrm{O}\right)$, and hexamethylene tetramine (HMTA) were acquired from Sinopharm Chemical Reagent Co. Ltd. (China). All the reagents were analytical grade and used without further purification. The solutions were prepared with deionized (DI) water.

\subsection{Preparation of $\mathrm{ZnO} / \mathrm{Ni}$ foam, G/Ni foam, and G/ZnO/Ni foam}

Four different composite electrodes, namely NF, G/NF, ZnO/NF, and $\mathrm{G} / \mathrm{ZnO} / \mathrm{NF}$ were fabricated. The square $\mathrm{Ni}$ foam $(1 \mathrm{~cm} \times 1$ 
$\mathrm{cm}$ ) was cleaned in acetone, $\mathrm{HCl}$, and ethanol, immersed in a solution containing $0.1 \mathrm{M}$ zinc acetate $\left[\mathrm{Zn}\left(\mathrm{CH}_{3} \mathrm{COO}\right)_{2}\right]$ for $3 \mathrm{~min}$, and annealed at $200{ }^{\circ} \mathrm{C}$ for $30 \mathrm{~min}$ to form $\mathrm{ZnO}$ seed layers. In the hydrothermal process, $50 \mathrm{mM} \mathrm{Zn}\left(\mathrm{NO}_{3}\right)_{2} \cdot 6 \mathrm{H}_{2} \mathrm{O}$ and $50 \mathrm{mM}$ HMTA were dissolved in deionized (DI) water. The $\mathrm{ZnO}$ seeded NF was placed in the precursor solution at $95{ }^{\circ} \mathrm{C}$ for $5 \mathrm{~h}$ and then annealed at $300{ }^{\circ} \mathrm{C}$ for $1 \mathrm{~h}$ to produce $\mathrm{ZnO}$-coated $\mathrm{NF}$ (labeled as $\mathrm{ZnO} / \mathrm{NF}$ ). Afterwards, $1 \mathrm{~mL}$ of the oily slurry of graphene was dispersed in $10 \mathrm{~mL}$ of ethanol by mild sonication to form solution $\mathrm{A}$. NF and $\mathrm{ZnO} / \mathrm{NF}$ were put into solution A under stirring for $2 \mathrm{~min}$ and dried at $60^{\circ} \mathrm{C}$ to produce graphene-coated $\mathrm{NF}$ (labeled as G/NF) and graphene-coated $\mathrm{ZnO} / \mathrm{NF}$ (labeled as $\mathrm{G} / \mathrm{ZnO} / \mathrm{NF}$ ).

\subsection{Preparation of palladium nanoparticles coated electrodes}

Electrochemical plating was adopted to produce the $\mathrm{Pd} / \mathrm{NF}, \mathrm{Pd} /$ $\mathrm{ZnO} / \mathrm{NF}, \mathrm{Pd} / \mathrm{G} / \mathrm{NF}$, and $\mathrm{Pd} / \mathrm{G} / \mathrm{ZnO} / \mathrm{NF}$ electrodes. The solution for palladium plating contained $2.7 \mathrm{mM} \mathrm{PdCl}_{2}, 0.35 \mathrm{M} \mathrm{NH} \mathrm{NH}_{4} \mathrm{Cl}$, and an appropriate amount of $\mathrm{NH}_{3} \cdot \mathrm{H}_{2} \mathrm{O}$ was added to adjust the $\mathrm{pH}$ to $8-9$. The electrodes and platinum were the cathode and anode, respectively, during electroplating in the palladium plating solution. The current density was at $10 \mathrm{~mA} \mathrm{~cm} \mathrm{~cm}^{-2}$ and electroplating time was $30 \mathrm{~min}$. The electrodes were removed, cleaned with deionized water, and dried for $30 \mathrm{~min}$ at $60{ }^{\circ} \mathrm{C}$ to produce $\mathrm{Pd} / \mathrm{NF}, \mathrm{Pd} / \mathrm{ZnO} / \mathrm{NF}, \mathrm{Pd} / \mathrm{G} / \mathrm{NF}$, and $\mathrm{Pd} / \mathrm{G} / \mathrm{ZnO} / \mathrm{NF}$. The schematic diagram of $\mathrm{Pd} / \mathrm{G} / \mathrm{ZnO} / \mathrm{NF}$ electrode formation is shown in Fig. 1, and the steps of other electrode formation can be removed accordingly.

\subsection{Apparatus and measurement procedures}

The morphology and microstructure of the electrodes were characterized by scanning electron microscopy (FE-SEM, Hitachi S-4800) and Field-emission transmission electron microscope (TEM/HRTEM, JEM 2100F), energy-dispersive X-ray spectroscopy (EDS Type GENESIS 60) and the crystal structure the chemical states was investigated by X-ray diffraction (XRD, Rigaku, RINT2000, $\mathrm{Cu} \mathrm{K}_{\alpha 1}$ radiation, $\lambda=0.154 \mathrm{~nm}$ ) and X-ray photoelectron spectroscopy (XPS, ESCALAB250Xi). Elemental composition was determined by the inductively coupled plasma mass-spectrometer (ICP-MS, Elan DRC II PerkinElmer SCIEX). The electrochemical tests were carried out on the CHI660D electrochemical workstation (Shanghai Chenhua CHI660D) in the three-electrode mode. The fabricated electrodes served as the working electrodes, whereas the saturated calomel electrode (SCE) and platinum electrode were the reference and counter electrodes, respectively. The electrochemical properties were determined by cyclic voltammetry (CV), linear sweep voltammetry (LSV), and electrochemical impedance spectroscopy (EIS). The CV data were obtained in the potential window between -1.4 and $0.6 \mathrm{~V} v s$. SCE at scanning rates from 10 to $100 \mathrm{mV} \mathrm{s}^{-1}$. EIS was conducted at the open circuit potential with a $5 \mathrm{mV}$ perturbation amplitude and the frequency range was from $10^{5}$ to $10^{-1} \mathrm{~Hz}$. The electrochemical measurements were performed in $1 \mathrm{M} \mathrm{KOH}$ at room temperature $\left(25^{\circ} \mathrm{C}\right)$.

\section{Results and discussion}

\subsection{Structural characterization}

The surface morphology of $\mathrm{Pd} / \mathrm{NF}, \mathrm{ZnO} / \mathrm{NF}, \mathrm{G} / \mathrm{ZnO} / \mathrm{NF}$ and $\mathrm{Pd} / \mathrm{G} /$ $\mathrm{ZnO} / \mathrm{NF}$ was examined by scanning electron microscopy (SEM) as shown in Fig. 2. The macroporous topography of the $\mathrm{Pd} / \mathrm{G} / \mathrm{ZnO} /$ NF electrode is shown in Fig. 2a, where a layer of fluffy, porous material is clearly visible on the surface of the nickel foam. The microstructure of the fabricated $\mathrm{Pd} / \mathrm{NF}$ composite is a dense layer of Pd nanoparticles attached to the nickel foam, while the size of the Pd nanoparticles is $40-80 \mathrm{~nm}$ (Fig. 2b). It can be clearly seen that some Pd nanoparticles agglomerate. There are needle-like ZnO nanowires uniformly distributed on the nickel foam according to Fig. $2 c$ and a higher-magnification SEM image (inset of Fig. 2c) further revealed the specific surface area of the electrode can be enhanced by the needle-like structure of $\mathrm{ZnO}$. Fig. 2d depicts the SEM image of $\mathrm{G} / \mathrm{ZnO} / \mathrm{NF}$ electrode. Graphene sheets whose size is about $2 \mu \mathrm{m}$ can be clearly observed on the surface of $\mathrm{ZnO}$ nanowires. Fig. 2e and f show different magnification SEM diagrams of $\mathrm{Pd} / \mathrm{G} / \mathrm{ZnO} / \mathrm{NF}$ electrode. In Fig. $2 \mathrm{~d}$ and $\mathrm{f}$, it can be seen that large multilayer graphene nanosheets are unevenly distributed and agglomerated due to dip preparation.

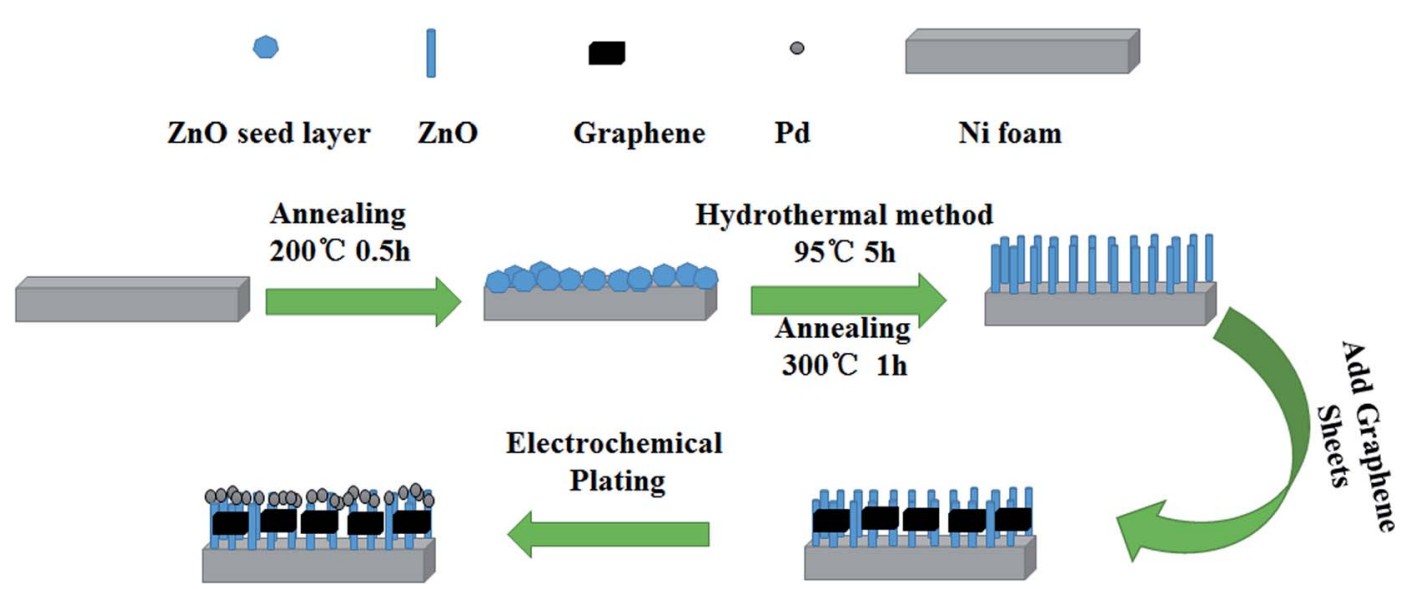

Fig. 1 The schematic depiction of $\mathrm{Pd} / \mathrm{G} / \mathrm{ZnO} / \mathrm{NF}$ electrode formation. 


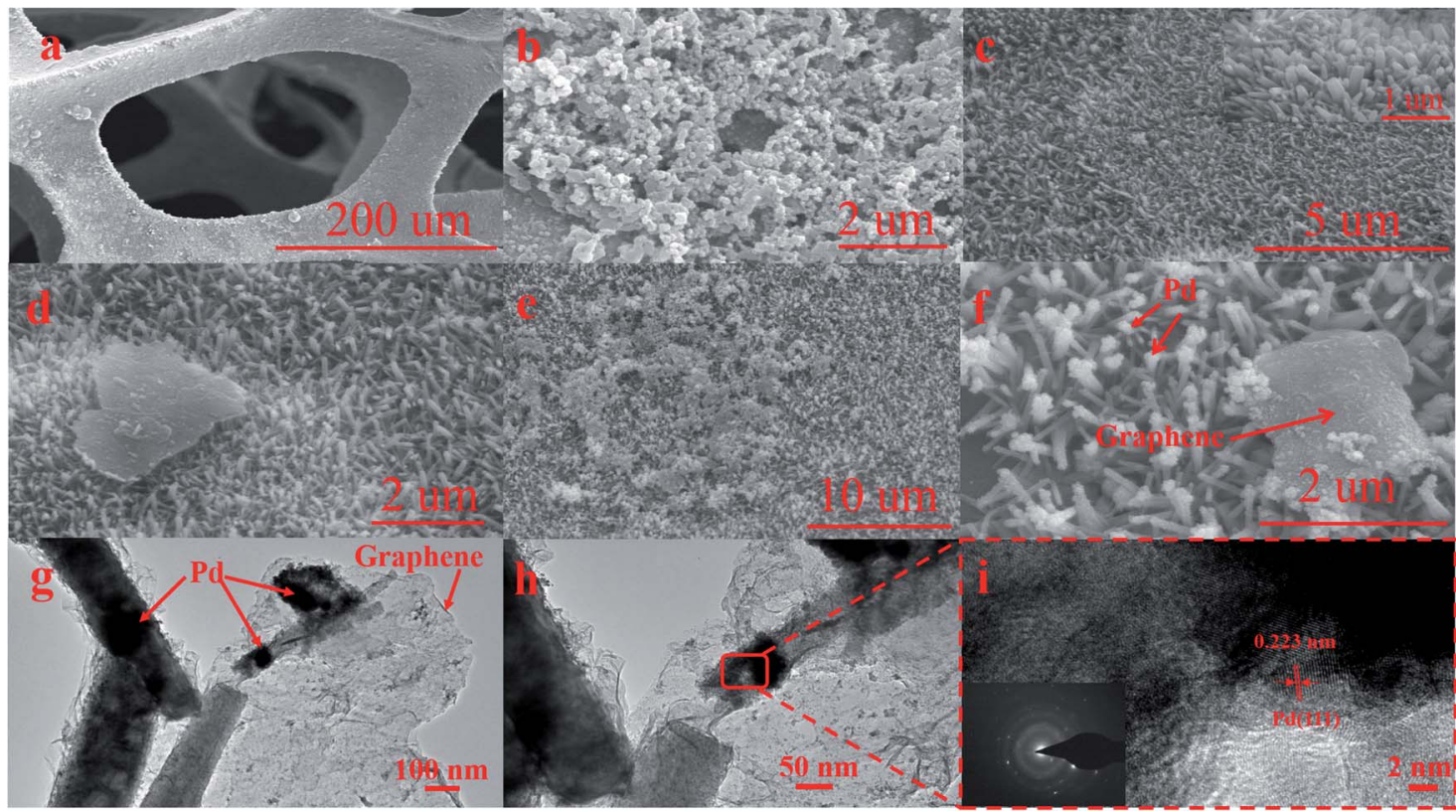

Fig. 2 (a) and (b) SEM images of $\mathrm{Pd} / \mathrm{G} / \mathrm{ZnO} / \mathrm{NF}$ and $\mathrm{Pd} / \mathrm{NF}$, (c) SEM images of $\mathrm{ZnO} / \mathrm{NF}$ and inset is higher magnification SEM image of ZnO/NF, (d) SEM image of G/ZnO/NF, (e) and (f) SEM images of Pd/G/ZnO/NF with different magnification, (g) and (h) TEM images of Pd/G/ZnO/NF, (i) HRTEM image of $\mathrm{Pd} / \mathrm{G} / \mathrm{ZnO} / \mathrm{NF}$, inset is $\mathrm{SAED}$ of $\mathrm{Pd} / \mathrm{G} / \mathrm{ZnO} / \mathrm{NF}$.

As shown in Fig. 2e (a higher-magnification SEM image of Fig. 2a), Pd nanoparticles were evenly deposited on the surface of $\mathrm{G} / \mathrm{ZnO} / \mathrm{NF}$ with some cracks and gaps. Bumps and hollows were observed that Pd nanoparticles were partly on graphene sheets and partly on the top of ZnO nanowires with larger magnification (Fig. 2f), suggesting an increased specific surface area of the electrode after the electrodeposition of Pd. Moreover, Pd nanoparticles distribution on the electrode were more uniform than that in Pd/NF (Fig. 2b), which was attributed to the acicular structure of $\mathrm{ZnO}$. Growth of Pd nanoparticles on graphene nanowires and $\mathrm{ZnO}$ nanowires was confirmed by Transmission electron microscopy (TEM) and High resolution TEM (HRTEM) for Pd/G/ZnO/NF (Fig. 2g-i). The TEM images in Fig. $2 g$ and $h$ show the diameter of the Pd nanoparticles is $40-80 \mathrm{~nm}$ and the morphology of Pd nanoparticles is spherical. HRTEM showed the lattice fringe of $0.223 \mathrm{~nm}$, consistent with the Pd (111) plane (Fig. 2i). The selected area electron diffraction (SAED) pattern (inset of Fig. 2i) shows a clear polycrystalline structure.

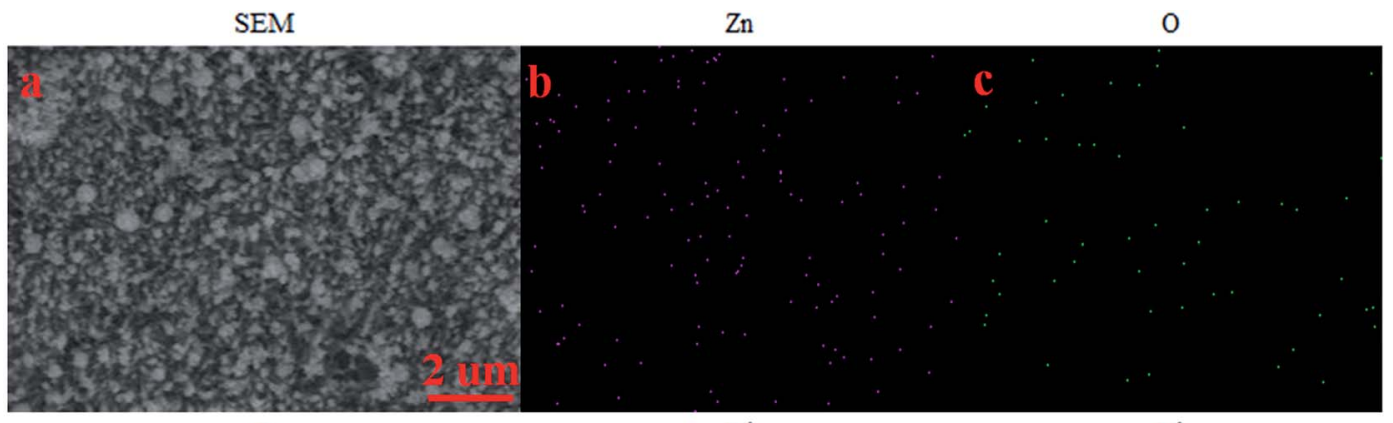

C

Pd

$\mathrm{Ni}$

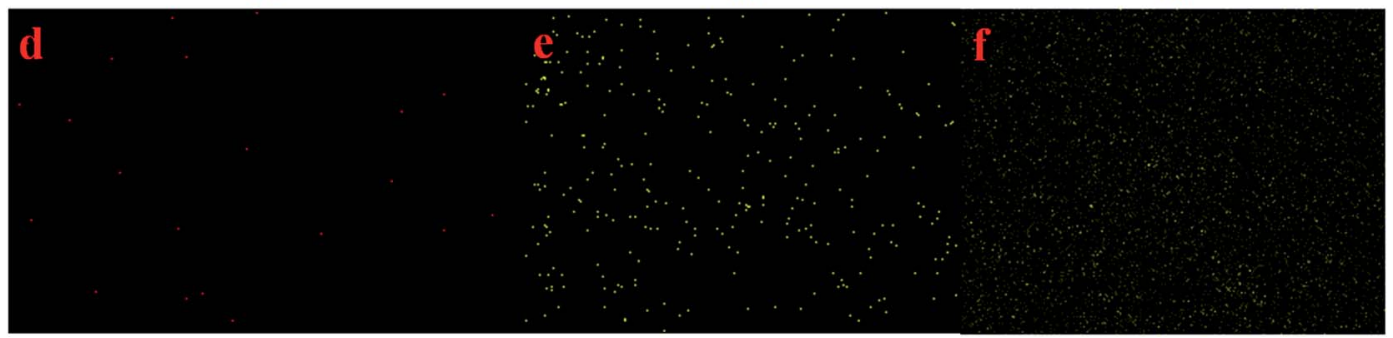

Fig. 3 (a) SEM image, (b-f) corresponding EDS mapping of the $\mathrm{Pd} / \mathrm{G} / \mathrm{ZnO} / \mathrm{NF}$ electrode. 


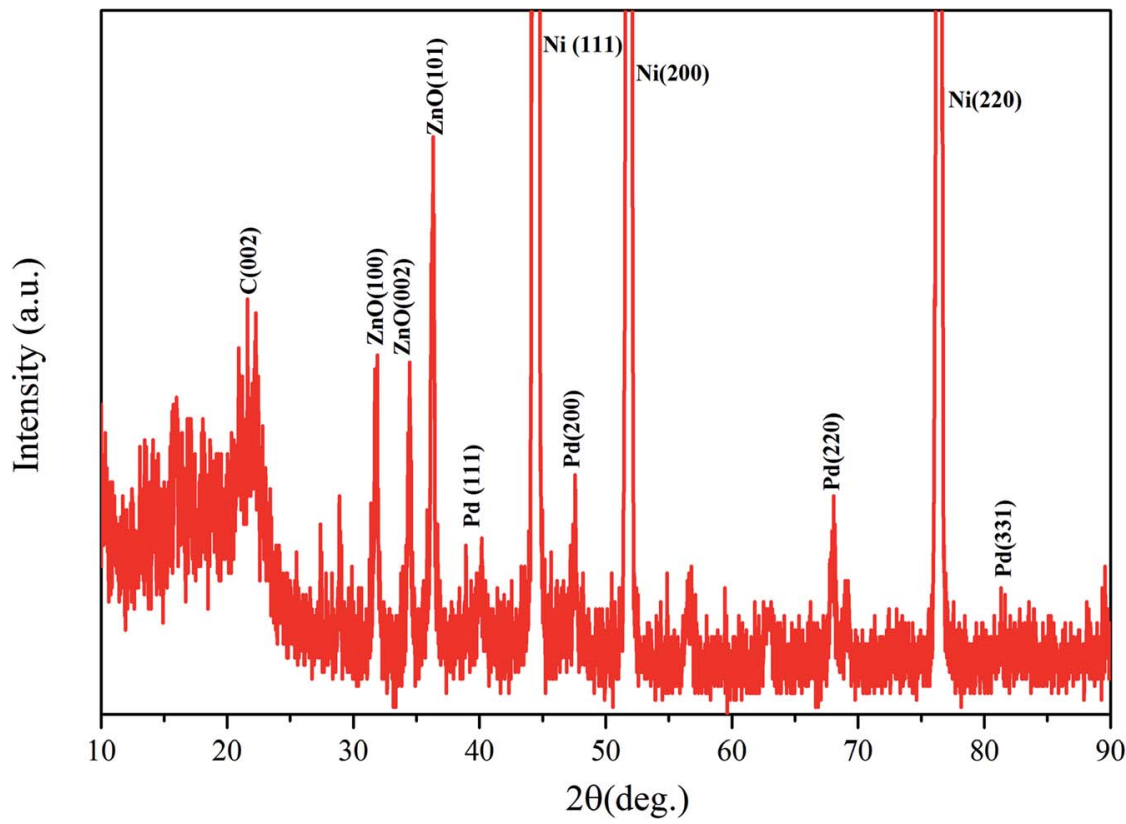

Fig. $4 \mathrm{XRD}$ spectrum of $\mathrm{Pd} / \mathrm{G} / \mathrm{ZnO} / \mathrm{NF}$.

Fig. 3 investigate the element distribution of the $\mathrm{Pd} / \mathrm{G} / \mathrm{ZnO} / \mathrm{NF}$ electrode by EDS mapping. Fig. 3a shows SEM micrographs of the microstructural features in the $\mathrm{Pd} / \mathrm{G} / \mathrm{ZnO} / \mathrm{NF}$ electrode, and corresponding EDS mapping was shown in Fig. $3 \mathrm{~b}-\mathrm{f}$, thus disclosing the presence of Zn, O, Ni, C, and Pd elements. Fig. 3d shows a small amount of element $\mathrm{C}$ due to the small amount of graphene added.

The crystal structure of the $\mathrm{Pd} / \mathrm{G} / \mathrm{ZnO} / \mathrm{NF}$ electrode is characterized by XRD as shown in Fig. 4 . The peaks of the face-
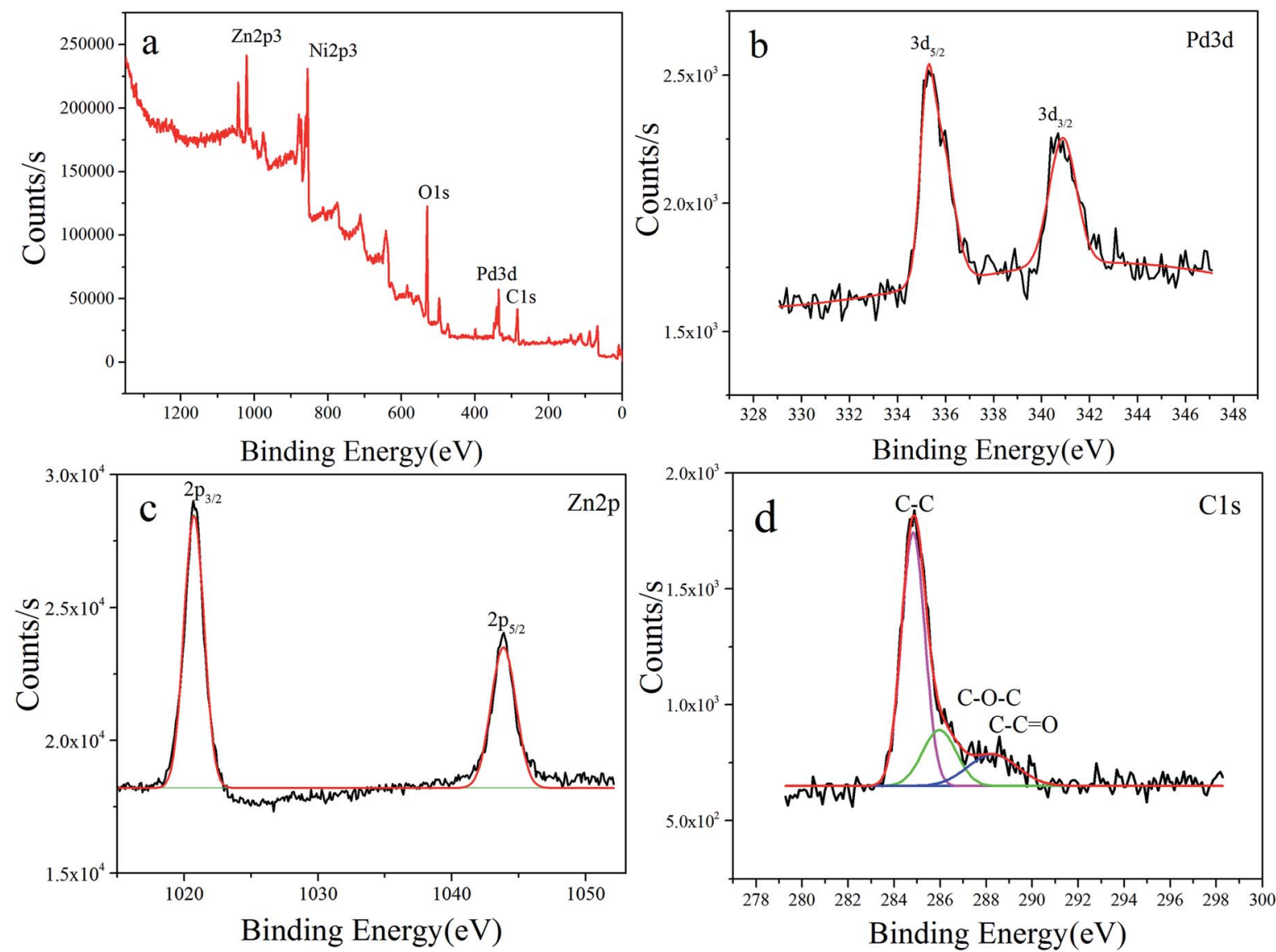

Fig. 5 (a) XPS spectrum of Pd/G/ZnO/NF, (b) XPS spectrum of Pd, (c) XPS spectrum of ZnO, and (d) XPS spectrum of graphene. 

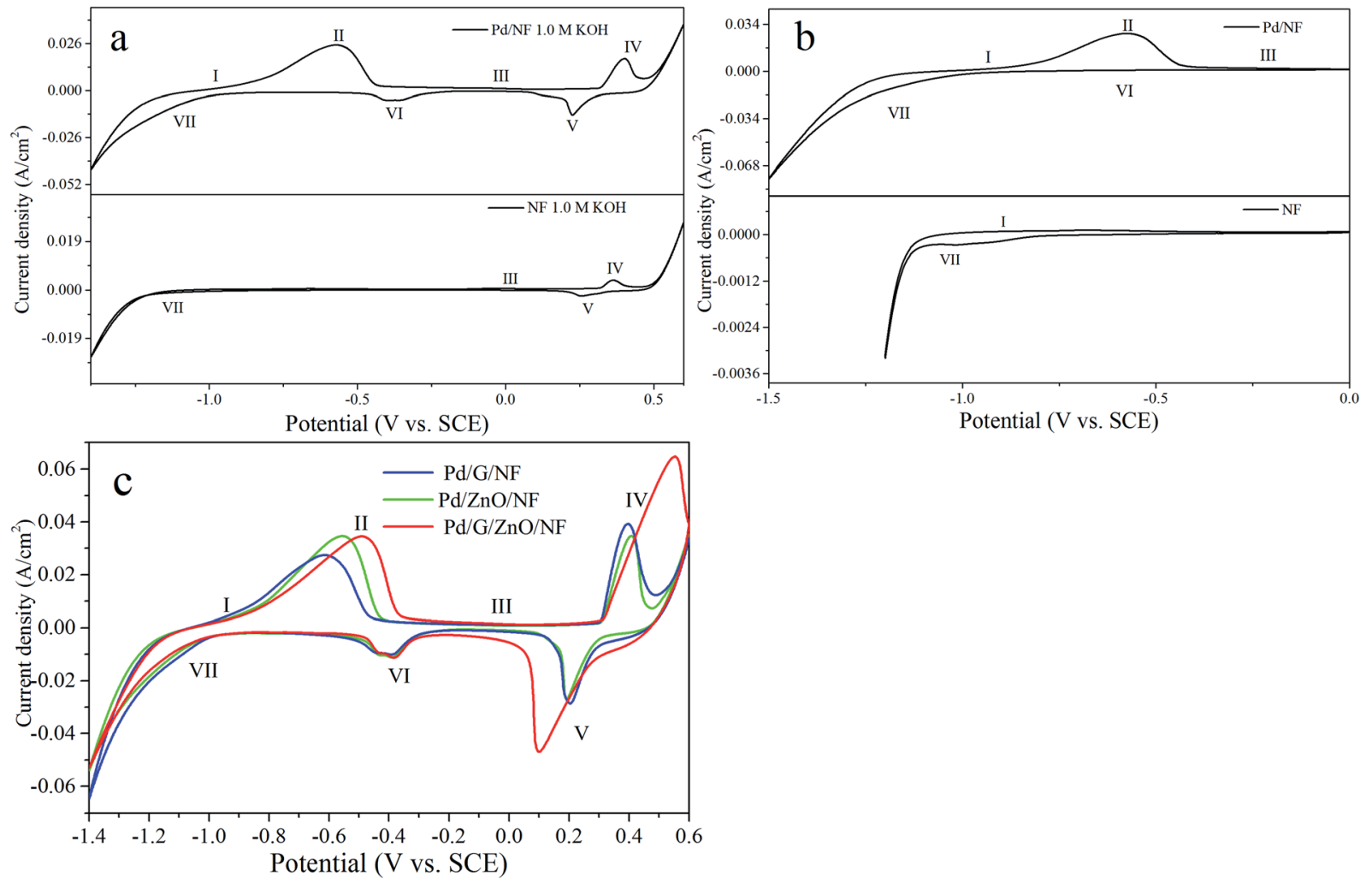

Fig. 6 (a) $C V$ of NF and Pd/NF in the potential region between -1.4 and $0.6 V$ vs. SCE, (b) $C V$ of $N F$ and Pd/NF in the related negative potential region between -1.5 and $0 \mathrm{~V} v$ s. SCE, (c) $\mathrm{CV}$ of $\mathrm{Pd} / \mathrm{G} / \mathrm{NF}, \mathrm{Pd} / \mathrm{ZnO} / \mathrm{NF}$, and $\mathrm{Pd} / \mathrm{G} / \mathrm{ZnO} / \mathrm{NF}$ in the potential region between -1.4 and $0.6 \mathrm{~V}$ vs. SCE at a scanning rate $10 \mathrm{mV} \mathrm{s}^{-1}$.

centered cubic structure at $44.6^{\circ}, 51.6^{\circ}$ and $76.3^{\circ}$ can be assigned to (111), (200) and (220) planes of the nickel substrate, respectively. The face-centered cubic Pd metal shows characteristic peaks at $2 \theta=40.1^{\circ}, 46.3^{\circ}, 68.3^{\circ}$, and $81.8^{\circ}$ corresponding to the (111), (200), (220), and (311) planes. The other diffraction peak at $21.6^{\circ}$ is the characteristic peak of graphene. The presence of the graphene peak at this location may be due to its oxidation and reduction in the air. The three diffraction peaks at $31.9^{\circ}, 34.2^{\circ}$, and $36.3^{\circ}$ correspond to the (100), (002), and (101) planes of the ZnO nanowires array, respectively.

XPS analysis was carried out to understand the surface chemical state of $\mathrm{Pd} / \mathrm{G} / \mathrm{ZnO} / \mathrm{NF}$ electrode. Fig. 5a shows $\mathrm{Ni}$, $\mathrm{Pd}, \mathrm{Zn}, \mathrm{O}$, and $\mathrm{C}$ originating from the Ni foam substrate, graphene, $\mathrm{ZnO}$, and Pd. Fig. $5 \mathrm{~b}$ shows that the binding energies of the major spin-orbit split doublet $\left(\mathrm{Pd} 3 \mathrm{~d}_{5 / 2}\right.$ and $\mathrm{Pd} 3 \mathrm{~d}_{3 / 2}$ ) of $\mathrm{Pd} / \mathrm{G} / \mathrm{ZnO} / \mathrm{NF}$ are $335.3 \mathrm{eV}$ and $340.7 \mathrm{eV}$, respectively, in good agreement with metallic $\operatorname{Pd}(0){ }^{7}$ Fig. $5 \mathrm{c}$ shows that the peaks of $\mathrm{Zn} 2 \mathrm{p}$ have binding energies of $1020.73 \mathrm{eV}$ and $1043.85 \mathrm{eV}$ attributed to $\mathrm{Zn} 2 \mathrm{p}_{3 / 2}$ and $\mathrm{Zn} 2 \mathrm{p}_{1 / 2}$ corresponding to $\mathrm{Zn}$ (II) in $\mathrm{ZnO}$. The $\mathrm{C} 1 \mathrm{~s}$ spectrum in Fig. $5 \mathrm{~d}$ can be fitted with three peaks at $284.8 \mathrm{eV}, 286.5 \mathrm{eV}$, and $288 \mathrm{eV}$ related to $\mathrm{C}-\mathrm{C}, \mathrm{C}-\mathrm{O}-\mathrm{C}$, and $\mathrm{C}-\mathrm{C}=\mathrm{O}$, respectively, consistent with the literature. ${ }^{5}$ The peak of $\mathrm{C} 1$ indicates that the graphene part has been oxidized.

\subsection{Cyclic voltammetry characterization of $\mathrm{Pd} / \mathrm{G} / \mathrm{ZnO} / \mathrm{NF}$}

Fig. 6a shows that cyclic voltammograms (CV) were obtained from the $\mathrm{Pd} / \mathrm{NF}$ and $\mathrm{NF}$ electrodes in the potential range between -1.4 and $0.6 \mathrm{~V} v$ s. SCE at a scanning rate of $10 \mathrm{mV} \mathrm{s}^{-1}$. It can be seen that a number of redox peaks are attributed to different electrochemical processes occurring at the surface of the electrode. The CV curves in the potential range between -1.5 and $0 \mathrm{~V} v s$. SCE are showed in Fig. $6 \mathrm{~b}$. The shape of the voltammograms is the same for all cycles (between $1^{\text {st }}$ and $50^{\text {th }}$ ) and only the peak current changes during the potential sweep. In case of NF electrode (the bottom side of Fig. 6a and b), peak I at the potential range between -0.8 and $-0.7 \mathrm{~V} v s$. SCE is appeared owing to the formation of $\alpha-\mathrm{Ni}(\mathrm{OH})_{2}$ (eqn (1)) during the first positive potential scan. Peak III appeared from 0 to $0.1 \mathrm{~V} v$ s. SCE originates from the transformation of $\alpha-\mathrm{Ni}(\mathrm{OH})_{2}$ $\rightarrow \beta-\mathrm{Ni}(\mathrm{OH})_{2}$ species (eqn (2)). With the potential moving to more positive values, a pair of redox peaks (IV and V) are ushered in, which are the mutual transformation of $\beta-\mathrm{Ni}(\mathrm{OH})_{2}$ and $\beta-\mathrm{NiOOH}$ (eqn (3) and (4)). In the potential range between -1.1 and $-1 \mathrm{~V}$ vs. SCE, the cathodic peak VII is a reduced process of $\beta-\mathrm{Ni}(\mathrm{OH})_{2}$ (eqn (5)). The corresponding voltammetric results can be described by the following reactions:

$$
\begin{gathered}
\mathrm{Ni}+2 \mathrm{OH}^{-} \rightarrow \alpha-\mathrm{Ni}(\mathrm{OH})_{2}+2 \mathrm{e}^{-} \\
\alpha-\mathrm{Ni}(\mathrm{OH})_{2}+n \mathrm{Ni}+2 n \mathrm{OH}^{-} \rightarrow(n+1) \beta-\mathrm{Ni}(\mathrm{OH})_{2}+2 n \mathrm{e}^{-}
\end{gathered}
$$



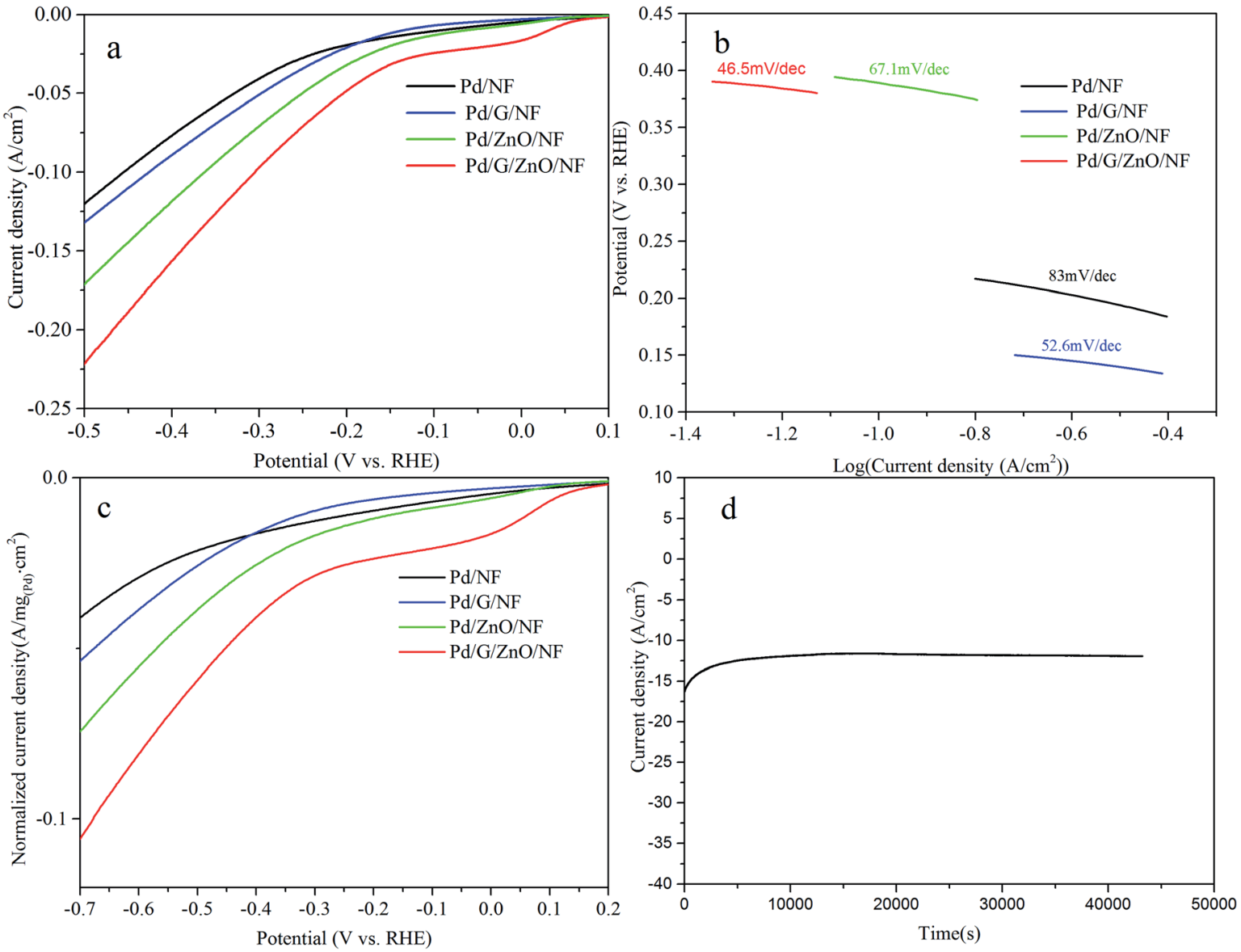

Fig. 7 (a) LSV polarization curve of $\mathrm{Pd} / \mathrm{NF}, \mathrm{Pd} / \mathrm{G} / \mathrm{NF}, \mathrm{Pd} / \mathrm{ZnO} / \mathrm{NF}$, and $\mathrm{Pd} / \mathrm{G} / \mathrm{ZnO} / \mathrm{NF}$ at a scanning rate of $10 \mathrm{mV} \mathrm{s} \mathrm{s}^{-1}$ and (b) corresponding Tafel plots, (c) the LSV of the catalysts with normalized current density by Pd mass, (d) chronoamperometric curves $(/-t)$ of $\mathrm{Pd} / \mathrm{G} / \mathrm{ZnO} / \mathrm{NF}$.

$$
\begin{gathered}
\beta-\mathrm{Ni}(\mathrm{OH})_{2}+\mathrm{OH}^{-} \rightarrow \beta-\mathrm{NiOOH}+\mathrm{H}_{2} \mathrm{O}+\mathrm{e}^{-} \\
\beta-\mathrm{NiOOH}+\mathrm{H}_{2} \mathrm{O}+\mathrm{e}^{-} \rightarrow \beta-\mathrm{Ni}(\mathrm{OH})_{2}+\mathrm{OH}^{-} \\
\beta-\mathrm{Ni}(\mathrm{OH})_{2}+2 \mathrm{e}^{-} \rightarrow \mathrm{Ni}+2 \mathrm{OH}^{-}
\end{gathered}
$$

For the Pd/NF electrode (Fig. 6a), it is no need to repeat the explanation of the same reaction mechanism as the NF electrode. According to eqn (6), an anode peak II at potential of approximately $-0.65 \mathrm{~V}$ vs. SCE is appeared owing to the desorption of diffusional hydrogen absorbed in Pd nanoparticles' lattice interstices. The oxide state of palladium (PdO) (eqn (7)) appears at peak III, which overlapping with the electrochemical transformation process of $\alpha-\mathrm{Ni}(\mathrm{OH})_{2}$ into $\beta$ $\mathrm{Ni}(\mathrm{OH})_{2}$. Peak VI originates from the reaction in which PdO is reduced to Pd (eqn (8)) while peak VII which starts from -1.4 to $-1 \mathrm{~V}$ vs. SCE can be attributed to the hydrogen absorption process (eqn (9)) on the surface of Pd nanoparticles which overlapping with the reduced process of $\beta-\mathrm{Ni}(\mathrm{OH})_{2}$. As shown in Fig. 6b, owning to the absence of oxidation state of Pd at the limited upper potential, the reduction peak of PdO disappears during the decreasing potential scans.

$$
\begin{gathered}
\mathrm{PdH}+\mathrm{OH}^{-} \rightarrow \mathrm{H}_{2} \mathrm{O}+\mathrm{Pd}+\mathrm{e}^{-} \\
\mathrm{Pd}+2 \mathrm{OH}^{-} \rightarrow \mathrm{PdO}+\mathrm{H}_{2} \mathrm{O}+2 \mathrm{e}^{-} \\
\mathrm{PdO}+\mathrm{H}_{2} \mathrm{O}+2 \mathrm{e}^{-} \rightarrow \mathrm{Pd}+2 \mathrm{OH}^{-} \\
\mathrm{Pd}+\mathrm{H}_{2} \mathrm{O}+\mathrm{e}^{-} \rightarrow \mathrm{PdH}+\mathrm{OH}^{-}
\end{gathered}
$$

Fig. 6c compares the cyclic voltammetry (CV) curves of Pd/G/ $\mathrm{NF}, \mathrm{Pd} / \mathrm{ZnO} / \mathrm{NF}$, and $\mathrm{Pd} / \mathrm{G} / \mathrm{ZnO} / \mathrm{NF}$ in the potential range of -1.4 to $0.6 \mathrm{~V} v s$. SCE at a scanning rate of $10 \mathrm{mV} \mathrm{s}^{-1}$. The same $\mathrm{CV}$ shape is observed from the electrodes in this potential range. In these CV curves, the adsorption/absorbed hydrogen peak current of the NF is weakest in all electrodes obviously while the hydrogen peak current of the other three electrodes $(\mathrm{Pd} / \mathrm{G} / \mathrm{NF}, \mathrm{Pd} / \mathrm{ZnO} / \mathrm{NF}, \mathrm{Pd} / \mathrm{G} / \mathrm{ZnO} / \mathrm{NF})$ are almost identical. It can be said that no hydrogen evolution reaction took place on the surface of the NF electrode. For the peak II, the highest peak current density of $\mathrm{Pd} / \mathrm{G} / \mathrm{ZnO} / \mathrm{NF}$ results from the higher electrochemical activity because of the large surface area of $\mathrm{ZnO}$ and high conductivity of graphene.

Fig. 7a shows linear sweep voltammetry (LSV) obtained from $\mathrm{Pd} / \mathrm{NF}, \mathrm{Pd} / \mathrm{G} / \mathrm{NF}, \mathrm{Pd} / \mathrm{ZnO} / \mathrm{NF}$, and $\mathrm{Pd} / \mathrm{G} / \mathrm{ZnO} / \mathrm{NF}$ ) in $1 \mathrm{M} \mathrm{KOH}$ at a scanning rate of $10 \mathrm{mV} \mathrm{s}^{-1}$ and Fig. $7 \mathrm{~b}$ shows the 

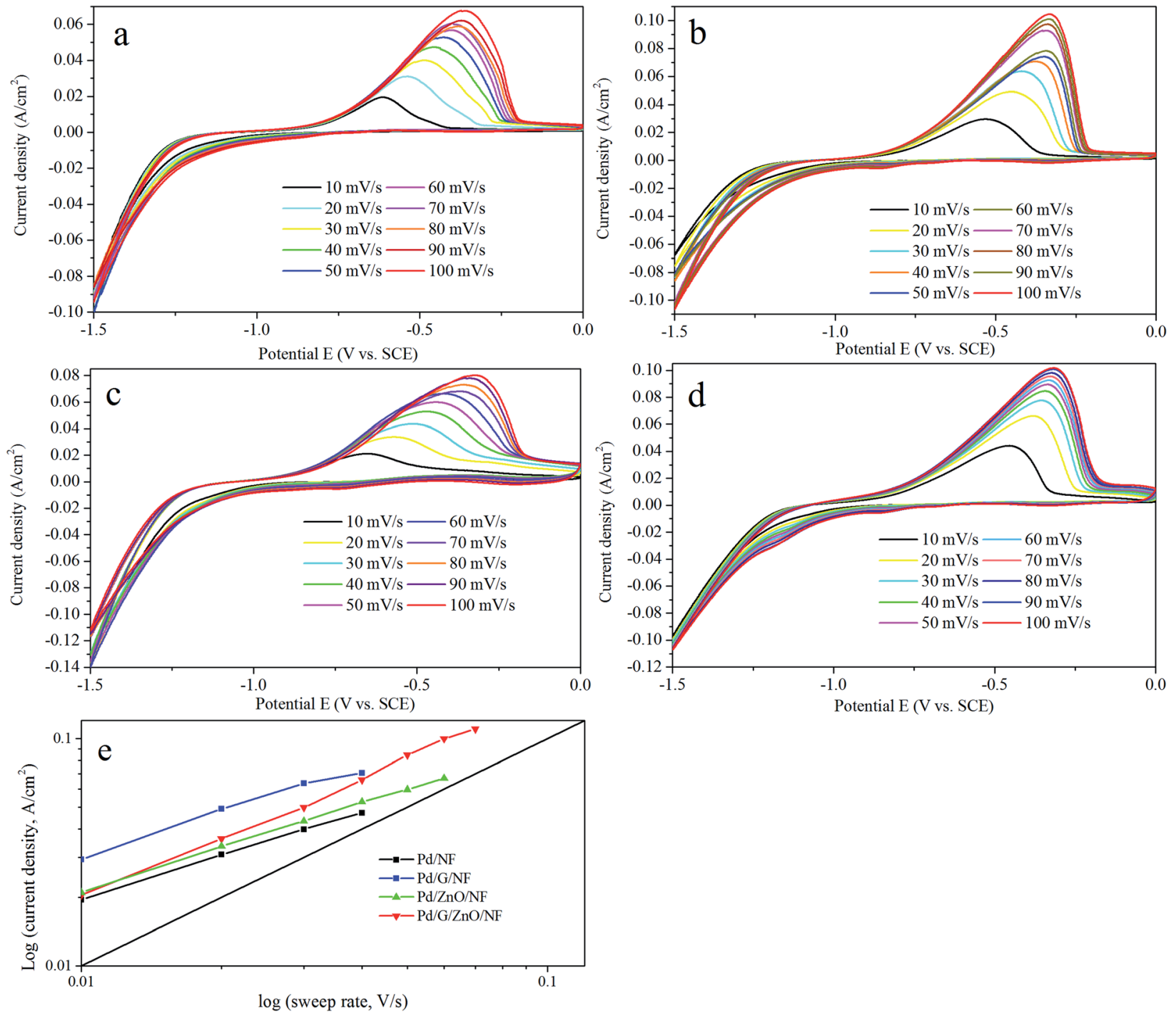

Fig. $8 \mathrm{CV}$ of (a) Pd/NF, (b) Pd/G/NF, (c) Pd/G/ZnO/NF, and (d) Pd/G/ZnO/NF in the potential range between -1.5 and 0 V vs. SCE for different scanning rates in $1 \mathrm{M} \mathrm{KOH}$; (e) relationship between the anodic peak current densities and scanning rates for different samples.

corresponding Tafel plots. The LSV and Tafel data are shown in the reversible hydrogen electrode (RHE) potential for simplicity. ${ }^{15}$ Therefore, the zero of overpotential can be determined at $1.067 \mathrm{~V} v s$. SEC due to the electrochemical test are done in $1 \mathrm{M} \mathrm{KOH}$ solution $(\mathrm{pH} \sim 14)$. More importantly, overpotential is an important indicator of hydrogen evolution
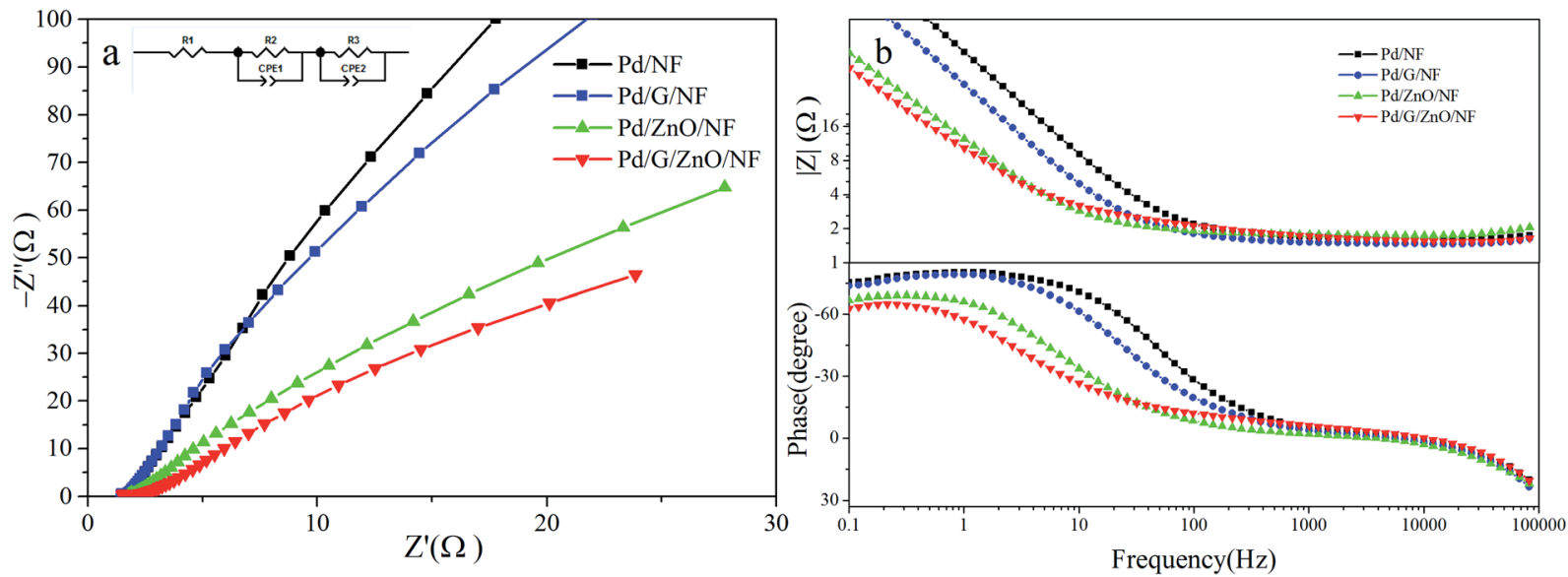

Fig. 9 (a) Nyquist and (b) Bode plots of Pd/NF, Pd/G/NF, Pd/ZnO/NF, and the inset of (a) the equivalent circuit diagram of Pd/G/ZnO/NF. 
ability, that is, the smaller the overpotential, the better the hydrogen evolution performance. The overpotentials of $\mathrm{Pd} / \mathrm{NF}$, $\mathrm{Pd} / \mathrm{G} / \mathrm{NF}, \mathrm{Pd} / \mathrm{ZnO} / \mathrm{NF}$, and $\mathrm{Pd} / \mathrm{G} / \mathrm{ZnO} / \mathrm{NF}$ ) are, respectively, $-125 \mathrm{mV},-91 \mathrm{mV},-80 \mathrm{mV}$, and $-31 \mathrm{mV}$ at a cathodic current density of $10 \mathrm{~mA} \mathrm{~cm}^{-2}$ and the overpotential of $\mathrm{Pd} / \mathrm{G} / \mathrm{ZnO} / \mathrm{NF}$ is the smallest. At a large cathodic current density such as $100 \mathrm{~mA}$ $\mathrm{cm}^{-2}$, the overpotential of $\mathrm{Pd} / \mathrm{G} / \mathrm{ZnO} / \mathrm{NF}$ is $-306 \mathrm{mV}$ that is smaller than those of $\mathrm{Pd} / \mathrm{ZnO} / \mathrm{NF}(-363 \mathrm{mV}), \mathrm{Pd} / \mathrm{G} / \mathrm{NF}(-427$ $\mathrm{mV})$, and $\mathrm{Pd} / \mathrm{NF}(-427 \mathrm{mV})$ again showing $\mathrm{Pd} / \mathrm{G} / \mathrm{ZnO} / \mathrm{NF}$ has the highest electrocatalytic activity. The corresponding Tafel slope is obtained by fitting the linear region in the LSV curve to the Tafel equation. The Tafel slope of $\mathrm{Pd} / \mathrm{G} / \mathrm{ZnO} / \mathrm{NF}\left(46.5 \mathrm{mV} \mathrm{dec}^{-1}\right)$ is smaller than those of the other electrocatalysts for $\mathrm{Pd} / \mathrm{NF}$

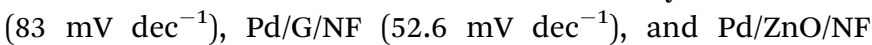
$\left(67.1 \mathrm{mV} \mathrm{dec}{ }^{-1}\right)$. The Tafel slope is in good agreement with the LSV data confirming the good HER characteristics of Pd/G/ $\mathrm{ZnO} / \mathrm{NF}$. The content of Pd in the four electrodes was investigated by ICP-MS. The loading mass of Pd nanoparticles on the $\mathrm{Pd} / \mathrm{G} / \mathrm{ZnO} / \mathrm{NF}$ electrode was $0.45 \mathrm{mg}\left(0.45 \mathrm{mg} \mathrm{cm}^{-2}\right)$, which was similar to that of the $\mathrm{Pd} / \mathrm{ZnO} / \mathrm{NF}$ electrode $0.44 \mathrm{mg}(0.44 \mathrm{mg}$ $\left.\mathrm{cm}^{-2}\right)$, the $\mathrm{Pd} / \mathrm{G} / \mathrm{NF}$ electrode $0.44 \mathrm{mg}\left(0.44 \mathrm{mg} \mathrm{cm}^{-2}\right)$ and the $\mathrm{Pd} / \mathrm{NF}$ electrode $0.43 \mathrm{mg}\left(0.43 \mathrm{mg} \mathrm{cm}^{-2}\right)$, respectively. Fig. 7c exhibits the LSV of the catalysts with normalized current density by the loading Pd mass. The Pd/G/ZnO/NF shows much higher normalized current density than others at the same potential, the results are good for hydrogen evolution reaction. Fig. $7 d$ shows the stability test of $\mathrm{Pd} / \mathrm{G} / \mathrm{ZnO} / \mathrm{NF}$ electrode at overpotential $0.4 \mathrm{~V}$ for 12 hours. The change of current density is normal at the beginning, possibly without deaeration of the electrode or the reduction of oxide on the electrode surface. The current density after initial period remained stable, which proved the excellent stability of the $\mathrm{Pd} / \mathrm{G} / \mathrm{ZnO} / \mathrm{NF}$ electrode.

Fig. 8a-d show the electrochemical properties of $\mathrm{Pd} / \mathrm{NF}, \mathrm{Pd} /$ $\mathrm{G} / \mathrm{NF}, \mathrm{Pd} / \mathrm{ZnO} / \mathrm{NF}$, and $\mathrm{Pd} / \mathrm{G} / \mathrm{ZnO} / \mathrm{NF}$ are examined between -1.5 and $0 \mathrm{~V} v$ s. SCE at scanning rates between 10 and $100 \mathrm{mV}$ $\mathrm{s}^{-1}$ in $1 \mathrm{M} \mathrm{KOH}$. Oxidation-reduction of $\mathrm{Pd}$ nanoparticles is avoided by selecting the upper limit potential $0 \mathrm{~V} v s$. SCE. The samples yield similar cyclic voltammograms and show the oxidation-reduction behavior in this potential region. There are two anodic peaks associated with the formation of passive $\alpha$ $\mathrm{Ni}(\mathrm{OH})_{2}$ amorphous layer (I) and oxidation of adsorbed hydrogen on the Pd nanoparticles (II). However, it is almost impossible to see peak I and the reduction peak of PdO disappears during the decreasing potential scans due to the absence

Table 1 Comparison of HER activity of $\mathrm{Pd} / \mathrm{G} / \mathrm{ZnO} / \mathrm{NF}$ with other catalysts

\begin{tabular}{|c|c|c|c|}
\hline Working electrode & $\begin{array}{l}\text { Tafel slope } \\
\left(\mathrm{mV} \mathrm{dec}^{-1}\right)\end{array}$ & $\begin{array}{l}\text { Overpotential/current } \\
\text { density }(\mathrm{mV}) /\left(\mathrm{mA} \mathrm{cm}^{-2}\right)\end{array}$ & Ref. \\
\hline $\mathrm{Pd} / \mathrm{G} / \mathrm{ZnO} / \mathrm{NF}$ & 46.5 & $31 / 10$ & This work \\
\hline rGO-Au ${ }_{48} \mathrm{Pd}_{52}$ & 149 & $130 / 10$ & 8 \\
\hline $\mathrm{Pd}_{x} \mathrm{Cu}_{100-x} / \mathrm{C}$ & 48 & $102 / 10$ & 9 \\
\hline $\mathrm{Pd}_{17} \mathrm{Se}_{15}$ & 57 & $182 / 10$ & 15 \\
\hline $\mathrm{PdBi}_{2}$ & 63 & $78 / 10$ & 18 \\
\hline
\end{tabular}

of oxidation state of $\mathrm{Pd}$ in the limited upper potential. The reduction peak (VII) increases gradually according to Fig. 8a-d. As the electrochemical rate increases, oxidation of adsorbed hydrogen on the Pd nanoparticles corresponding to the fully anodic peaks (II) even at the large sweep rate is improved. It can be concluded that the combination of $\mathrm{ZnO}$, graphene, and $\mathrm{Pd}$ facilitates hydrogen evolution.

Fig. 8e shows that the current densities of anodic peak II $(j$, with the unit of $\left.\mathrm{A} \mathrm{cm}^{-2}\right)$ change with the sweeping rates $v\left(\mathrm{~V} \mathrm{~s}^{-1}\right)$ as the plot of $\log (j)$ versus $\log (v)$. Moreover, there is a line with a slope of 1 for comparison. The transfer coefficient is close to 1 for the $\mathrm{Pd} / \mathrm{G} / \mathrm{ZnO} / \mathrm{NF}$ electrode for sweeping rates from 10 to $100 \mathrm{mV} \mathrm{s}^{-1}$ because oxidation of adsorbed hydrogen on the Pd surface is a surface-controlled process. ${ }^{16}$ The slopes of Pd/NF, $\mathrm{Pd} / \mathrm{G} / \mathrm{NF}$, and $\mathrm{Pd} / \mathrm{ZnO} / \mathrm{NF}$ are $0.6,0.64$, and 0.7 respectively, which are smaller than that of $\mathrm{Pd} / \mathrm{G} / \mathrm{ZnO} / \mathrm{NF}$, indicative of the high resistance.

\subsection{Impedance measurements}

Electrochemical impedance spectroscopy (EIS) which is a powerful technique to study the electrode kinetics in $\mathrm{HER}^{17,18}$ is performed on $\mathrm{Pd} / \mathrm{NF}, \mathrm{Pd} / \mathrm{G} / \mathrm{NF}$, and $\mathrm{Pd} / \mathrm{ZnO} / \mathrm{NF}$ and $\mathrm{Pd} / \mathrm{G} /$ $\mathrm{ZnO} / \mathrm{NF}$ in the range of $10^{5}$ to $10^{-1} \mathrm{~Hz}$ at the open circuit potential with an AC excitation signal of $5 \mathrm{mV}$ in $1 \mathrm{M} \mathrm{KOH}$. Fig. 9a and b show the impedance diagrams as plots of Nyquist and Bode planes. The electrochemical resistance of the hydrogen reduction reaction on $\mathrm{Pd} / \mathrm{G} / \mathrm{ZnO} / \mathrm{NF}$ is less than that on the other electrodes and the electrochemical impedance of $\mathrm{Pd} / \mathrm{NF}$ is the biggest. The $\mathrm{Pd} / \mathrm{G} / \mathrm{ZnO} / \mathrm{NF}$ electrode is smaller than the other electrodes as shown in Fig. $9 \mathrm{~b}$. The results reveal that the HER activity is markedly improved by incorporating $\mathrm{ZnO}$ and graphene into $\mathrm{Pd} / \mathrm{NF}$. The inset of Fig. 9a presents the equivalent circuit and the fitting equivalent circuit is consistent with the experimental data. LSV is an important parameter to measure the effects of the hydrogen evolution reaction. The properties of Pd-based catalysts in the literature are compared in Table 1 which shows that the overpotential of $\mathrm{Pd} / \mathrm{G} / \mathrm{ZnO} / \mathrm{NF}$ is the smallest $(31 \mathrm{mV})$ among the five electrodes at a current density is $10 \mathrm{~mA} \mathrm{~cm}^{-2}$. The Tafel slope (46.5 $\mathrm{mV} \mathrm{dec}^{-1}$ ) of $\mathrm{Pd} / \mathrm{G} /$ $\mathrm{ZnO} / \mathrm{NF}$ is the smallest among these electrodes. Therefore, $\mathrm{Pd} /$ $\mathrm{G} / \mathrm{ZnO} / \mathrm{NF}$ electrode has excellent hydrogen evolution performance, and the preparation method is simple, economical, and eco-friendly.

\section{Conclusion}

Pd nanoparticles are electrodeposited on graphene-coated $\mathrm{ZnO}$ on Ni foam. Cyclic voltammetry, Tafel plots, and electrochemical impedance spectroscopy are performed to determine the HER properties in $1 \mathrm{M} \mathrm{KOH}$. The $\mathrm{Pd} / \mathrm{G} / \mathrm{ZnO} / \mathrm{NF}$ electrode shows high conductivity and stability by cyclic voltammetry in addition to enhanced electrocatalytic hydrogen evolution as indicated by an overpotential of $31 \mathrm{mV}$ and Tafel slope of $46.5 \mathrm{mV} \mathrm{dec}^{-1}$ at $10 \mathrm{~mA} \mathrm{~cm}^{-2}$. Our results disclose that $\mathrm{Pd} / \mathrm{G} /$ $\mathrm{ZnO} / \mathrm{NF}$ has outstanding catalytic activity and stability in HER rendering it promising in hydrogen production. 


\section{Conflicts of interest}

There are no conflicts to declare.

\section{Acknowledgements}

We would like to thank the technology Innovation Center of Agricultural Multi-Dimensional Sensor Information Perception, Heilongjiang Province. This work was jointly supported by the University Nursing Program for Young Scholars with Creative Talents in Heilongjiang Province (Grant No. UNPYSCT2016087), Scientific Research Foundation for the Returned Overseas Chinese Scholars in Heilongjiang Province, Project of Plant food Processing Technology-Heilongjiang Province superiority and characteristic discipline (Grant No. YSTSXK201873), Fundamental Research Funds in Heilongjiang Provincial Universities (No. 135109244, 135309115, 135309211).

\section{References}

1 Z. Guoqiang, L. Yue and R. Kun, Epitaxial Growth of $\mathrm{Ni}(\mathrm{OH})_{2}$ Nanoclusters on $\mathrm{MoS}_{2}$ Nanosheets for Enhanced Alkaline Hydrogen Evolution Reaction, Nanoscale, 2018, 10(40), 19074-19081.

$2 \mathrm{X}$. Chen, K. Yu and Y. Shen, Synergistic Effect of $\mathrm{MoS}_{2}$ Nanosheets and $\mathrm{VS}_{2}$ for Hydrogen Evolution Reaction with Enhanced Humidity Sensing Performance, ACS Appl. Mater. Interfaces, 2017, 9(48), 42139-42148.

3 P. S. Toth, M. Velicky and T. J. A. Slater, Hydrogen evolution and capacitance behavior of $\mathrm{Au} / \mathrm{Pd}$ nanoparticle-decorated graphene heterostructures, Applied Materials Today, 2017, 8, 125-131.

4 B. Rezaei, M. Mokhtarianpour and A. A. Ensafi, Hydrogen evolution reaction and formic acid oxidation by decorated nanostructural $\mathrm{Pt} / \mathrm{Pd}$ on a copper-filled nanoporous stainless steel, J. Iran. Chem. Soc., 2018, 15(4), 955-965.

5 S. Ghasemi, S. R. Hosseini and S. Nabipour, Palladium nanoparticles supported on graphene as an efficient electrocatalyst for hydrogen evolution reaction, Int. J. Hydrogen Energy, 2015, 40(46), 16184-16191.

6 B. B. Li, S. Z. Qiao and X. R. Zheng, Pd coated $\mathrm{MoS}_{2}$ nanoflowers for highly efficient hydrogen evolution reaction under irradiation, J. Power Sources, 2015, 284, 68-76.

7 B. Li, R. Wang and X. Shao, Synergistically enhanced photocatalysis from plasmonics and a co-catalyst in
$\mathrm{Au} @ Z n O-P d$ ternary core-shell nanostructures, Inorg. Chem. Front., 2017, 4(12), 2088-2096.

8 J. A. S. B. Cardoso, L. Amaral and Ö. Metin, Reduced graphene oxide assembled Pd-based nanoalloys for hydrogen evolution reaction, Int. J. Hydrogen Energy, 2017, 42(7), 3916-3925.

9 X. Zhang, D. Wu and D. Cheng, Component-dependent electrocatalytic activity of PdCu bimetallic nanoparticles for hydrogen evolution reaction, Electrochim. Acta, 2017, 246, 572-579.

10 Z. Sun, X. Wei and H. Shen, Preparation and evaluation of $\mathrm{Pd} /$ polymeric pyrrole-sodium lauryl sulfonate/foam-Ni electrode for 2,4-dichlorophenol dechlorination in aqueous solution, Electrochim. Acta, 2014, 129, 433-440.

11 Y. Koskun, A. Savk and B. Sen, Highly sensitive glucose sensor based on monodisperse palladium nickel/activated carbon nanocomposites, Anal. Chim. Acta, 2018, 1010, 37-43.

12 H. Tian, H. Fan and J. Ma, Noble metal-free modified electrode of exfoliated graphitic carbon nitride/ZnO nanosheets for highly efficient hydrogen peroxide sensing, Electrochim. Acta, 2017, 247, 787-794.

13 C. Tang, N. Cheng and Z. Pu, NiSe Nanowire Film Supported on Nickel Foam: An Efficient and Stable 3D Bifunctional Electrode for Full Water Splitting, Angew. Chem., 2015, 127(32), 9483-9487.

14 S. Masudy-Panah, Y. J. K. Eugene and N. D. Khiavi, Aluminum-incorporated $\mathrm{p}-\mathrm{CuO} / \mathrm{n}-\mathrm{ZnO}$ photocathode coated with nanocrystal-engineered $\mathrm{TiO}_{2}$ protective layer for photoelectrochemical water splitting and hydrogen generation, J. Mater. Chem. A, 2018, 6(25), 11951-11965.

15 S. Kukunuri, P. M. Austeria and S. Sampath, Electrically Conducting Palladium Selenide $\left(\mathrm{Pd}_{4} \mathrm{Se}, \mathrm{Pd}_{17} \mathrm{Se}_{15}, \mathrm{Pd}_{7} \mathrm{Se}_{4}\right)$ Phases: Synthesis and Activity Towards Hydrogen Evolution Reaction, Chem. Commun., 2016, 52, 206-209.

16 M. Anand Raj and S. Arumainathan, Comparative Study of Hydrogen Evolution Behavior of Nickel Cobalt and Nickel Cobalt Magnesium Alloy Film Prepared by Pulsed Electrodeposition, Vacuum, 2018, 160, 461-466.

17 C. Hu, Y. Tian and J. Wang, Structural evolution and optical properties of hydrogenated germanium carbonitride films, Vacuum, 2016, 129, 23-30.

18 F. Li, J. Li and X. Lin, Designed synthesis of multi-walled carbon nanotubes@Cu@ $\mathrm{MoS}_{2}$ hybrid as advanced electrocatalyst for highly efficient hydrogen evolution reaction, J. Power Sources, 2015, 300, 301-308. 